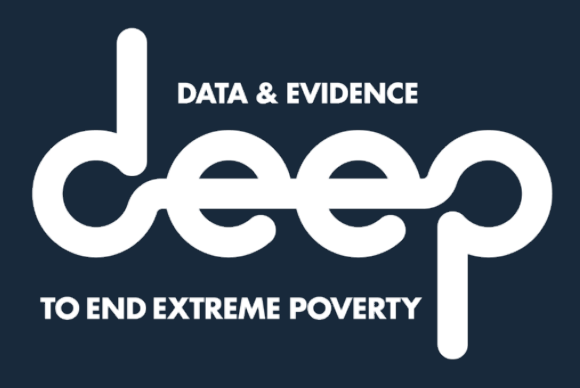

\title{
What works to reduce extreme poverty? A selective review
}

Molly Doruska and John Hoddinott

November 2020

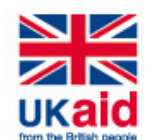




\section{About DEEP}

Our mission is to build evidence, insights, and solutions that help end extreme poverty globally.

We aim to contribute to new global and national data and evidence that governments, decision makers, citizens and researchers can use to improve people's lives and support the world's poorest people in their efforts to escape extreme poverty.

We are a consortium of the Universities of Cornell, Copenhagen, and Southampton led by Oxford Policy Management, in partnership with the World Bank's Development Data Group and funded by the UK Foreign, Commonwealth \& Development Office.

Suggested Citation: Doruska, M. and Hoddinott, J. (2020) What works to reduce extreme poverty? A selective review. DEEP Working Paper 01. Data and Evidence to end Extreme Poverty Research Programme: Oxford. Available at: https://doi.org/10.55158/DEEPWP1

Corresponding Author: John Hoddinott - Division of Nutritional Sciences and Charles $\mathrm{H}$. Dyson School of Applied Economics and Management, Cornell University. Email jfh246@cornell.edu

Follow the project here:

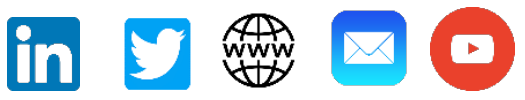




\section{Abstract}

1. We undertook a selective, structured literature review of what works to reduce poverty.

2. We did this for three reasons. First, we want to understand what has already been done so that we do not duplicate existing work. Second, we want to identify gaps where new work would be of value. Third, we want to create a global public good - a resource that can be used by the UK Foreign, Commonwealth and Development Office (FCDO) and others.

3. This review covers research undertaken in five countries: Bangladesh, Ethiopia, Madagascar, Mozambique, and Tanzania. Country selection was driven by the following considerations: We needed to ensure that we covered a range of countries, in regard to geography and income levels. We wanted to ensure that we had countries in both south Asia and sub-Saharan Africa. Lastly, we needed to keep this review tractable, given the time and resource constraints under which this work has taken place.

4. We examined three types of interventions that have plausible effects on poverty reduction: social protection; interventions that provide assets to poor households; and interventions that increase returns to assets.

5. We searched within Google Scholar and the World Bank e-Library for those studies that have an explicit focus on impacts on poverty, as measured by consumption. So, for example, a study that only reports the results of an agricultural intervention in terms of crop yields (i.e. increased returns to assets, here land) would not be included, because we do not know what impact this has on poverty, but a study that reports on an agricultural intervention that reduced poverty by increasing crop yields would be included.

6. Our initial screen identified papers that appeared to meet these criteria based on study title and abstract. We identified 111 such studies.

7. We then assessed each study against five inclusion criteria, eliminating studies if they did not meet all of them. These criteria were:

- studies that consider poverty impacts, directly through poverty, consumption, or assets;

- studies that contain methods suitable for causal inference;

- studies that are not based on simulations;

- studies that undertake an impact evaluation, potentially in addition to evaluating targeting and programme implementation; and 
- studies that consider measurable outcomes and not participant perceptions or preferences.

8. Only 42 of the initial studies met all of these criteria.

9. The distribution of these studies across our five countries is uneven. 17 out of 42 are from Bangladesh (40.4\%) and another 15 are from Ethiopia (35.7\%). Mozambique and Tanzania comprise the remaining $23.8 \%$. There are no studies that meet our inclusion criteria for Madagascar.

10. While we encountered many studies that assess the impact of social protection interventions (66), surprisingly relatively few (17) met our inclusion criteria. The studies assessing the poverty impacts of social protection interventions make up the largest proportion of selected studies, $40.4 \%$. Asset transfer studies are also well-represented, with 15 being included (35.7\%). However, there are only 10 studies that look at how interventions that aim to increase returns to existing assets can reduce poverty.

11. Ethiopia is the only country where we have selected studies covering social protection, asset transfer, and increasing returns to assets.

12. Asset transfers have been extensively studied in Bangladesh: nearly all (11 out of 14) of the asset transfer interventions that met our inclusion criteria are in Bangladesh.

13. Both Mozambique and Tanzania have two studies that examine social protection interventions.

14. Out of the 17 studies on interventions examining what works to reduce poverty in Bangladesh, only one includes an urban area.

15. Few studies, only five out of the 42 that met all inclusion criteria, assess whether evaluations of 'what works' to reduce poverty consider the depth and severity of poverty as well as its incidence.

16. Few studies show evidence of impacts disaggregated by sex.

17. Several studies looking at asset transfers consider the sustainability of impacts. Sustainability is rarely examined in studies looking at social protection or at increased returns to assets.

18. In an annexe to the paper, for each study that met all of the inclusion criteria, we provide a summary that includes the following information: the details of the intervention design; a description of the sample and evaluation design; the impacts on poverty, consumption, assets, and returns to assets; and whether the study reports on sustainability (the impacts on poverty after the intervention ended), the impacts on the extreme poor 
and/or on the depth of poverty, and gendered aspects of poverty (e.g. impact on women's consumption), and whether the results disaggregate by sex of household head. 


\section{Table of contents}

Abstract

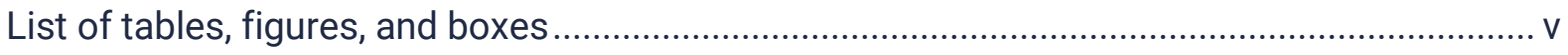

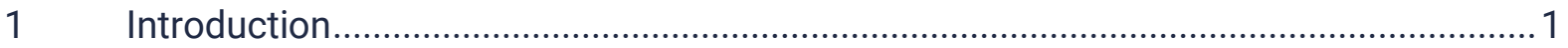

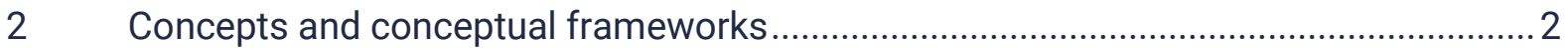

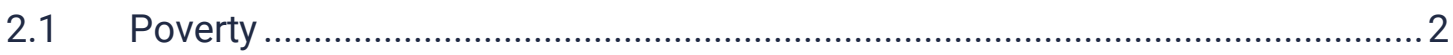

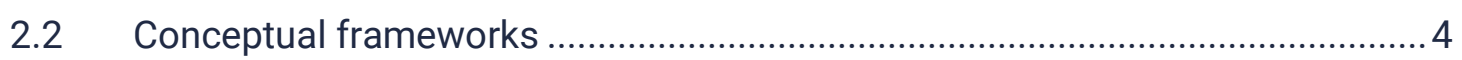

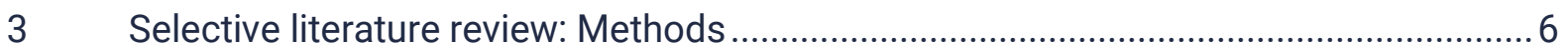

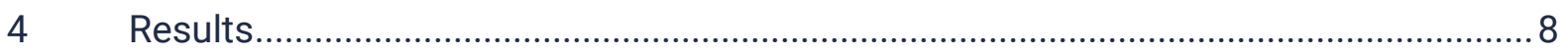

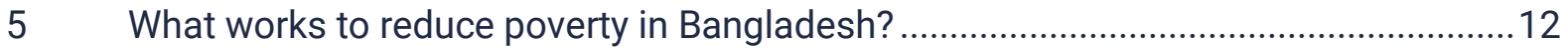

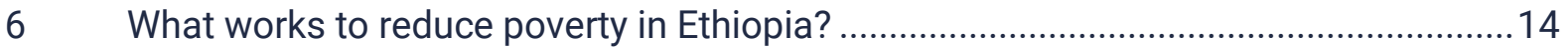

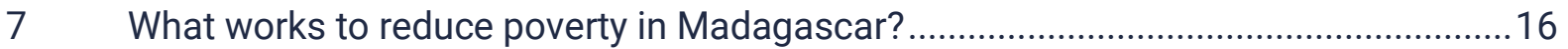

$8 \quad$ What works to reduce extreme poverty in Mozambique? ...........................................17

$9 \quad$ What works to reduce extreme poverty in Tanzania? ................................................17

10 What do we know about works to reduce extreme poverty in Bangladesh, Ethiopia, Madagascar, Mozambique, and Tanzania? ............................................................... 19

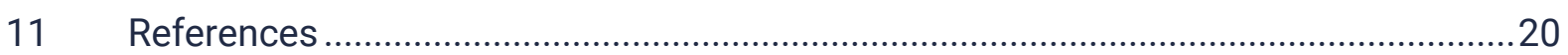




\section{List of tables, figures, and boxes}

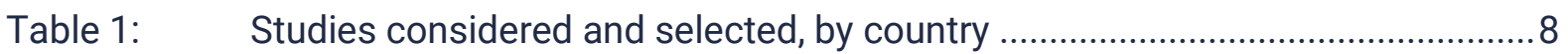

Table 2: $\quad$ Studies considered and selected, by topic......................................................... 8

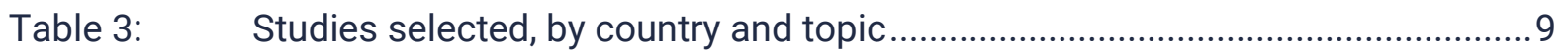

Table 4: $\quad$ Studies selected, by country, topic, and rural/urban status............................... 9

Table 5: $\quad$ Studies selected, by country, topic, and evidence of sustained impacts.........11

Table 6: $\quad$ Studies selected, by country, topic, and impact evaluation method ................11 


\section{Introduction}

The previous 30 years have seen unprecedented global progress in reducing extreme poverty. Between 1990 and 2015 the number of people living in extreme poverty fell from 1.9 billion to 700 million. Building on this achievement, the Sustainable Development Goals commit the world to 'end[ing] poverty in all its forms everywhere' by 2030 . However, there is increasing evidence that this aspirational goal will be difficult to achieve. Global growth has slowed, and the COVID-19 pandemic has adversely affected both developing and developed countries. Furthermore, there is suggestive evidence that more recent progress in poverty reduction has been of the low-hanging fruit variety. The chronically poor (those living in poverty over extended periods of time) and those living far below the poverty line now comprise the bulk of the remaining poor. This suggests that earlier tools for combatting poverty (such as broad-based growth) will perhaps be less effective in reaching the remaining poor. Thus, generating new evidence on 'what works' to tackle extreme poverty, for who, where, and how is of critical importance. It is within this context that the DEEP Research Consortium seeks to improve the measurement of extreme poverty; the identification of structural drivers of extreme poverty; and the design and implementation of effective programmes and strategies to tackle extreme poverty. DEEP works in eight countries, five in sub-Saharan Africa (Ethiopia, Madagascar, Mozambique, Nigeria, and Tanzania) and three in south Asia (Bangladesh, India, and Myanmar).

As part of the inception phase of DEEP we have undertaken a selective review of 'what works' to reduce extreme poverty in five of these countries: Bangladesh, Ethiopia, Madagascar, Mozambique, and Tanzania. Our rationale for doing so, and our rationale for our country selection, is threefold. First, we want to understand what has already been done so that we do not duplicate existing work. Second, we want to identify gaps where new work would be of value. Third, we want to create a global public good - a resource that can be used by the FCDO and others. Our country selection was driven by the following considerations. We needed to ensure that we covered a range of countries, in terms of geography and income levels. We wanted to ensure that we have countries in both south Asia and sub-Saharan Africa. And we needed to keep the review tractable, given the time and resource constraints under which this work has taken place. Hence, we include Bangladesh but not India - a review of what works to reduce poverty in India would be a paper in itself. We exclude Myanmar because our initial scan of the literature suggested that it was unlikely that there would be studies that met our inclusion criteria. We include four African countries - Ethiopia, Madagascar, Mozambique, and Tanzania - but not Nigeria. These four countries give us a range of African countries with different income levels, geographies, and histories. We exclude Nigeria for the same reason that we exclude India - given the time and resource constraints, we needed to keep our scope of work tractable. 
The selected review is structured as follows. We begin with a summary of poverty concepts and conceptual frameworks to identify an organising structure for our review. We then describe how we undertook this review: how we searched and how we decided which studies to include and which to exclude. Section 4 provides an overview of what we found, disaggregating studies both by country and whether the studies look at 'what worked' in terms of social protection, interventions that directly increased household asset holdings, and interventions that sought to increase returns to assets. On a country-by-country basis, we then summarise the literature we found. The last section, Section 10, summarises the review.

\section{Concepts and conceptual frameworks}

\subsection{Poverty}

There is an enormous literature on the history of poverty as a concept, on its philosophical underpinnings, and on its measurement: see, for example, Himmelfarb (1984), Ravallion (1994), Lipton and Ravallion (1995), and Ravallion (2015) for a discussion and summaries of key points. Rather than replicate these papers, we note the following.

First, following Lipton and Ravallion (1995), we define poverty as existing where a person's (or a household's) level of economic welfare is less than what is thought to be some reasonable minimum, either in absolute terms or in relation to the standards of a particular society. Economic welfare relates to the consumption of goods and services, and thus the 'reasonable minimum' refers to the realisation of a level of consumption that allows individuals to attain some basic level of wellbeing. As the Report of the Commission on Monitoring Global Poverty, the 'Atkinson Commission' (World Bank, 2017) notes, different countries and studies done in different countries arrive at different judgements about what constitutes these reasonable minima. Consequently, the International Poverty Line (US\$1.90 per person per day, adjusted for differences in purchasing power parity (PPP)), which is used to estimate the number of extreme poor globally, builds on national poverty lines from many (15) different developing countries.

Second, there are good reasons to consider multiple dimensions to poverty - see Alkire and Foster (2011), who build on Sen's (1985) work on capabilities. However, we give these measures limited attention in this paper. We note that Alkire and Foster (2011) incorporate consumption of goods and services as part of their measure, and that the non-monetary components of multi-dimensional poverty indices (such as schooling) often correlate with the monetary components. More importantly, improvements in non-monetary dimensions of 
poverty may require interventions across multiple sectors, which would make any review of 'what works' unwieldly. ${ }^{1}$

Third, we recognise that there are many non-trivial measurement errors associated with the implementation of a consumption-based poverty measure, including: the choice of metric (income or consumption); how to adjust for household size, composition, and lifecycle position; the selection and level of goods and services that contribute to the construction of the 'reasonable minimum' or poverty line (on this, also see World Bank (2017) for a recent discussion of these issues); and, finally, noting that although we define poverty in terms of individuals' consumption relative to some minimum, our data are nearly always at the household level, forcing us to make assumptions about the distribution of resources within the household (Lipton and Ravallion, 1995; Ravallion, 2015).

Following Ravallion (1994), Lipton and Ravallion (1995) define a measure of a person's living standard as C (e.g. consumption per capita). The poverty line is defined as z. A household is considered poor where $\mathrm{C}<\mathrm{z}$ and the prevalence of poverty is the fraction of a given population that is poor. The prevalence is often referred to as the 'headcount' measure of poverty. We can use this measure to assess the impact of interventions on poverty. Consider the following example. We have two households, $\mathrm{H} 1$ and $\mathrm{H} 2$, but only enough resources to transfer a small amount of income to one of them. $\mathrm{H} 1$ has a consumption level 'just below' the poverty line while $\mathrm{H} 2$ has a consumption level 'far below' the poverty line. If our goal is to 'reduce poverty', we should make the transfer to $\mathrm{H} 1$ as this will shift it from being poor to non-poor. Giving this transfer to $\mathrm{H} 2$ would increase its consumption but not enough to cross the poverty line. But seen from a broader perspective this seems perverse - a transfer aimed at reducing poverty is measured as successful when it neglects the very poorest. One way of addressing this is to explicitly consider the impact on the prevalence of poverty, the depth of poverty (the difference between household consumption levels and the poverty line - the poverty gap), and the severity of poverty (by considering the square of the poverty gap). The well-known Foster-Greer-Thorbecke (FGT) (1984) class of poverty measures are a formalisation of these ideas. If we want to understand what works to reduce extreme poverty then we are particularly interested in impacts on the severity of poverty: that is, the FGT P2 measure.

\footnotetext{
${ }^{1}$ Consider a multi-dimensional poverty index that consists of consumption levels and schooling. Reviewing 'what works' to improve such an index would require us to review the literature on what works to increase consumption as well as what works to increase schooling.
} 


\subsection{Conceptual frameworks}

There is no shortage of conceptual frameworks for understanding the causes of poverty. Here, we draw on common elements found in Baulch and Hoddinott (2000), as modified by Hoddinott and Quisumbing (2010) and Hoddinott (2012), Barrett and Carter (2006), and the Sustainable Livelihoods framework used extensively by the UK Department for International Development (DFID) (now the FCDO) (DFID, 1997; and Carney et al., 1999) over the last 20 years. There are five components: 'settings' (or 'contexts', or, using the language of Sustainable Lives, 'transforming structures and policies'); 'assets'; 'labour'; 'activities'; and 'outcomes'.

Settings describe the environment in which a household resides. Households exist within five settings: physical, social, political, legal, and economic. The physical setting refers to natural phenomena such as the level and variability of rainfall, the natural fertility of soils, distances to markets, and the quality of infrastructure. The social setting captures such factors as the existence of certain norms of behaviour and of social cohesion, and strife. The legal setting can be thought of as the general 'rules of the game' in which economic exchange takes place, which, in turn, is partly a function of the political setting that captures the mechanisms by which these rules are set. Finally, there is an economic setting that captures policies that affect the level, returns, and variability of returns on assets.

Within these settings, households have endowments of five types of assets - the Sustainable Livelihoods 'asset pentagon': physical capital (agricultural tools, livestock), natural capital (land), human capital (in the form of knowledge, skills, and health), financial capital (cash-in-hand, bank accounts, net loans outstanding), and social capital (networks, norms, and social trust that facilitates coordination and cooperation). All assets share a common characteristic, namely that alone or in conjunction with other assets they produce a stream of income over a period of time. Some assets have a second characteristic, namely that they are a store of value.

Households also have endowments of labour: time and effort that, in conjunction with the assets they hold, they allocate to income-generating activities. For a rural household, these might include the cultivation of food to meet subsistence food needs and cash crops for income. Alternatively, these can be disaggregated into non-agricultural and agricultural, with the latter disaggregated further by crop and livestock type. These allocations are based on the household's perception of the level of returns to these activities, as well as the variability of returns and their covariance. If they are concerned about the variability of returns, households might diversify their sources of income. For agricultural households, this might include off-farm activities (such as handicrafts or processing activities) or casual wage labour. The income that is generated by these activities partly reflects the amount of assets and labour used, but also the settings in which these activities take place. More specifically, 
the relationship between assets, labour, and activity choice, on the one hand, and income, on the other, is affected by the likelihood of a shock occurring, what Heitzmann et al. (2002) call a 'risk realization'. These could be shocks that emanate from the setting in which households are situated - a common or covariant shock - or they could be restricted to only this household - an idiosyncratic shock. As a simple example, consider a rural household that allocates natural capital (land), financial capital (to purchase inputs), human capital (farming knowledge), and labour to grow crops. If there is a major drought - a shock emanating from the physical setting - the return to these assets and labour will be zero and thus income from this activity will be zero. More generally, shocks can affect any or all of the components of our conceptual framework: settings, assets, or activities. For example, a flood can destroy parts of the physical setting (bridges, roads) and household assets (land, livestock, housing), which results in reductions in wage labour and other off-farm opportunities, reduced access to agricultural inputs, and difficulties in selling agricultural output.

Earned income from activities is one outcome. Consumption is another. However, the relationship is not one-to-one. For example, in response to shocks, households may draw down savings held in financial form, as livestock, as jewellery, or as other durables.

Alternatively, they may enter the credit market and borrow. They may alter investment in human capital: for example, by withdrawing girls from school. They may draw on private sources, such as remittances or gifts. Finally, governments may provide income transfers from social protection programmes.

Thus, we have the following relationships. Defining income as $\mathrm{Y}$, assets as $\mathrm{A}$, returns to assets as $\beta$, transfers as $T$, and $a$ as the marginal propensity to consume out of income:

$$
\begin{gathered}
Y=\beta A+T \\
\text { And } \\
C=a Y
\end{gathered}
$$

Several additional features and caveats should be noted. Assets are not static: changes in assets can come about either through household savings, as a result of shocks (as in the flooding example above), or as a result of a transfer from a government or other public agency. As Barrett and Carter (2005) state, households that can accumulate assets or that are able to increase returns to their assets will grow their way out of poverty: 'Among very poor populations, this growth could take some time, but movement nonetheless proceeds steadily in the right direction' (Barrett and Carter, 2005: 185). But there is no guarantee that such benign processes will necessarily take place. They note (p. 187) three reasons why this process of asset accumulation does not take place, resulting in some households remaining stuck in a poverty trap: (a) the underlying income-generating process may itself directly exhibit increasing returns to scale; (b) some high-return production processes may require a 
minimum size or scale such that only wealthier households can afford to switch to and adopt the high-return process; or (c) risk and financial market considerations may cause poor households to allocate their assets so as to reduce risk exposure, trading off expected returns for lower risk.

For the purposes of exposition, we have presented mechanisms for consumption smoothing as ex post responses to shocks. In practice, decisions regarding consumption are interlinked to decisions regarding income generation and perceptions of risk. Our conceptual framework treats the external environment as exogenous. Although this may be appropriate as a short-run assumption, one could argue that over the longer term the external environment can be altered by actions by the household (for example, where deforestation results from unsustainable forest use). Finally, an unattractive feature of this framework is that it treats the household as a single undifferentiated unit, despite much evidence questioning this assumption (Alderman et al., 1995). However, it is relatively straightforward to make the framework gender-sensitive.

Mindful of these caveats, this framework allows us to structure a micro-economic focus on 'what works' to reduce poverty. Specifically, within the settings in which households reside, governments, and the donor partners that they work with, can reduce poverty either by: increasing assets, $A$; increasing the returns to assets, $\beta$; and/or increasing transfers, $T$ (for example, through social protection interventions).

\section{Selective literature review: Methods}

Within the time constraints for this work, we undertook a selective, structured literature review. Specifically, we did the following:

1. We restricted the search to five of the eight countries covered by DEEP: Bangladesh, Ethiopia, Madagascar, Mozambique, and Tanzania. This selection was guided by the following considerations: (i) including countries in both south Asia and sub-Saharan Africa; and (ii) ensuring we included countries that typically receive less attention in the poverty literature, not just the 'usual suspects'. We excluded: Myanmar, based on an assumption that there is relatively little in the way of publicly funded anti-poverty interventions that have been rigorously assessed in that country; India, because a review of 'what works' in India would be a literature review all on its own; and Nigeria, because of time constraints (we will revisit this as the study advances).

2. We considered studies published between January 2010 and September 2020 (we are interested in recent evidence about 'what works').

3. We searched within two sources: Google Scholar and the World Bank e-Library. 
4. For each search term or compound search terms used, we assessed papers found in the first 10 pages of listed papers. In both Google Scholar and the World Bank e-Library, each page typically lists 10 studies, so this is equivalent to searching the first 100 titles for each search term (or compound search term used).

5. We focused on three classes of interventions: those that increase assets, those that increase returns to assets, and/or those that provide transfers.

6. We searched by country. For each study, we assessed whether the study has an explicit focus on impacts on poverty as measured by consumption. So, for example, a study that only reports the results of an agricultural intervention in terms of crop yields (i.e. increased returns to assets, here land) would not be included (because we do not know what impact this has on poverty) but a study that reports on an agricultural intervention that reduced poverty by increasing crop yields would be included.

7. We only included studies published in English.

Using these search parameters, we formed an initial list of studies that seemed to align with the objectives of our literature search. Inclusion in this list was based on the study's title, abstract, and any other information visible before downloading the study. We then carried out a careful assessment of each study, focusing on the introduction, methods, and impacts reported. We then assessed each study against five inclusion criteria, eliminating studies if they did not meet all of them. These criteria were:

- studies that consider poverty impacts, directly through poverty, consumption, or assets;

- studies that contain methods that are suitable for causal inference;

- studies that are not based on simulations;

- studies that undertake an impact evaluation, potentially in addition to evaluating targeting and programme implementation; and

- studies that consider measurable outcomes and not participant perceptions or preferences.

If a study was eliminated due to these criteria, it is considered a 'considered study'. Annex B lists all the considered studies that were not selected. The remaining studies are the 'considered and selected' group; we refer to this group below as 'selected' studies. The list of selected studies is given in Annex A.

For each study that meets these eligibility criteria, we note the following:

(a) details of the intervention design;

(b) description of the sample and the evaluation design;

(c) the impacts on poverty, consumption, assets, and returns to assets; 
(d) whether the study reports on: sustainability (impacts on poverty after the intervention ended); the impacts on the extreme poor and/or on the depth of poverty; and gendered aspects of poverty (e.g. impact on women's consumption); and whether the results are disaggregated by sex of the household head.

This information for the selected studies is presented in Annex C.

\section{Results}

We begin with a series of descriptive tables. Table 1 shows that, across all five countries, there were 111 studies that met our inclusion criteria based on title and abstract. These are the 'considered' studies. However, after a full text review, only 42 met the five inclusion criteria described above. These are the 'considered and selected' ('selected') studies. The distribution of these studies across our five countries is uneven. 17 out of 42 are from Bangladesh (40.4\%) and another 15 are from Ethiopia (35.7\%). Studies from Mozambique and Tanzania comprise the remaining $23.8 \%$. There are no studies that meet our inclusion criteria for Madagascar.

Table 1: Studies considered and selected, by country

$\begin{array}{lrr}\text { Bangladesh } & 37 & 17 \\ \text { Ethiopia } & 40 & 15 \\ \text { Madagascar } & 3 & 0 \\ \text { Mozambique } & 13 & 4 \\ \text { Tanzania } & 18 & 6 \\ \text { All } & 111 & 42\end{array}$

While we encountered many studies that assess the impact of social protection interventions (66), surprisingly relatively few (17) met our inclusion criteria. That said, these studies assessing the poverty impacts of social protection interventions make up the largest proportion of the selected studies, at $40.4 \%$. Asset transfer studies are also wellrepresented, with 15 being included (35.7\%). However, there are only 10 studies that look at how interventions aimed to increase returns to existing assets can reduce poverty.

Table 2: Studies considered and selected, by topic

$\begin{array}{lcc} & \text { Considered } & \text { Considered and selected } \\ \text { Social protection } & 66 & 17 \\ \text { Asset transfers } & 33 & 14 \\ \text { Increasing returns to assets } & 12 & 11 \\ \text { All } & \mathbf{1 1 1} & \mathbf{4 2}\end{array}$


In Table 3, we disaggregate the selected studies by topic and country. Ethiopia is the only country where we have selected studies covering social protection, asset transfer, and increasing returns to assets. Asset transfers have been extensively studied in Bangladesh; in fact, these make up nearly all (11 our 14) of the asset transfer interventions that met our inclusion criteria. Both Mozambique and Tanzania have two studies that examine social protection interventions.

Table 3: Studies selected, by country and topic

\begin{tabular}{|c|c|c|c|c|}
\hline & $\begin{array}{c}\text { Social } \\
\text { protection }\end{array}$ & Asset transfers & $\begin{array}{l}\text { Increasing } \\
\text { returns to } \\
\text { assets }\end{array}$ & Total \\
\hline \multicolumn{5}{|c|}{ Bangladesh } \\
\hline Considered & 20 & 17 & 0 & 37 \\
\hline Considered and selected & 6 & 11 & 0 & 17 \\
\hline \multicolumn{5}{|c|}{ Ethiopia } \\
\hline Considered & 26 & 8 & 6 & 40 \\
\hline Considered and selected & 7 & 3 & 5 & 15 \\
\hline \multicolumn{5}{|c|}{ Madagascar } \\
\hline Considered & 2 & 1 & 0 & 3 \\
\hline Considered and selected & 0 & 0 & 0 & 0 \\
\hline \multicolumn{5}{|c|}{ Mozambique } \\
\hline Considered & 8 & 2 & 3 & 13 \\
\hline Considered and selected & 2 & 0 & 2 & 4 \\
\hline \multicolumn{5}{|c|}{ Tanzania } \\
\hline Considered & 10 & 5 & 3 & 18 \\
\hline Considered and selected & 2 & 0 & 4 & 6 \\
\hline
\end{tabular}

We considered whether these studies cover only rural areas, only urban areas, or both. Table 4 tells us that work on poverty impacts is dominated by studies carried out solely in rural areas. These account for $76.2 \%$ (32/42) of our selected studies. Virtually all work on asset transfers (13/14 studies) has been done only in rural areas, as has the vast majority of work on increasing returns to assets (9/11 studies). Out of the 17 studies on intervention examining what works to reduce poverty in Bangladesh, only one includes an urban area.

Table 4: Studies selected, by country, topic, and rural/urban status

\begin{tabular}{lcccc} 
& $\begin{array}{c}\text { Social } \\
\text { protection }\end{array}$ & Asset transfers & $\begin{array}{c}\text { Increasing } \\
\text { returns to } \\
\text { assets }\end{array}$ & Total \\
\hline Urban only & 0 & 0 & 0 & 0 \\
Urban and rural & 1 & 0 & 0 & 1 \\
Rural only & 5 & 11 & 0 & 16
\end{tabular}




\begin{tabular}{|c|c|c|c|c|}
\hline & $\begin{array}{c}\text { Social } \\
\text { protection }\end{array}$ & Asset transfers & $\begin{array}{l}\text { Increasing } \\
\text { returns to } \\
\text { assets }\end{array}$ & Total \\
\hline \multicolumn{5}{|c|}{ Ethiopia } \\
\hline Urban only & 0 & 0 & 0 & 0 \\
\hline Urban and rural & 3 & 1 & 0 & 4 \\
\hline Rural only & 4 & 2 & 5 & 11 \\
\hline \multicolumn{5}{|c|}{ Madagascar } \\
\hline Urban only & 0 & 0 & 0 & 0 \\
\hline Urban and rural & 0 & 0 & 0 & 0 \\
\hline Rural only & 0 & 0 & 0 & 0 \\
\hline \multicolumn{5}{|c|}{ Mozambique } \\
\hline Urban only & 0 & 0 & 0 & 0 \\
\hline Urban and rural & 1 & 0 & 0 & 1 \\
\hline Rural only & 1 & 0 & 2 & 3 \\
\hline \multicolumn{5}{|c|}{ Tanzania } \\
\hline Urban only & 0 & 0 & 0 & 0 \\
\hline Urban and rural & 2 & 0 & 2 & 4 \\
\hline Rural only & 0 & 0 & 2 & 2 \\
\hline \multicolumn{5}{|c|}{ All } \\
\hline Urban only & 0 & 0 & 0 & 0 \\
\hline Urban and rural & 7 & 1 & 2 & 10 \\
\hline Rural only & 10 & 13 & 9 & 32 \\
\hline
\end{tabular}

We looked to see if these selected studies go beyond an assessment of immediate effects on poverty. As noted in our discussion of poverty concepts, it is of interest to assess whether evaluations of 'what works' to reduce poverty consider the depth and severity of poverty as well as its incidence. In practice, few studies do so: only five out of the 42 that were selected. We examined whether selected studies show evidence of impacts disaggregated by sex, but again we found few such studies. We also considered whether studies assess sustained impacts on poverty, where sustainability was defined in terms of observing impacts one year or more after the intervention ended. As Table 5 shows, in general, sustainability is often assessed for asset transfer interventions but is much less commonly assessed for those interventions that increased returns to assets or social protection. A caveat to note here, however, is that by design asset transfer interventions are short-lived. Households may participate in social protection interventions for a number of years and it may be that there are few studies that assess poverty impacts after participants leave, or graduate, from social protection programmes. 
Table 5: Studies selected, by country, topic, and evidence of sustained impacts

\begin{tabular}{lrcrc} 
& $\begin{array}{l}\text { Social } \\
\text { protection }\end{array}$ & Asset transfers & $\begin{array}{l}\text { Increasing } \\
\text { returns to } \\
\text { assets }\end{array}$ & Total \\
Bangladesh & Percentage of selected studies showing sustained impacts \\
Ethiopia & 0 & 73 & 0 & 47 \\
Madagascar & 0 & 67 & 40 & 27 \\
Mozambique & - & - & - & - \\
Tanzania & 0 & 0 & 0 & 0 \\
\hline
\end{tabular}

Notes: Sustained impacts are those reported one year or more after the intervention ended.

Finally, we tabulated the methods used in these evaluations (Table 6). Surprisingly, despite its widespread popularity in development work, randomised control trials (RCTs) are only used in about a quarter of the studies (10/42) that met our inclusion criteria. Matching methods are common, though this is driven largely by a large number of Ethiopian studies that use this approach. There are no studies that use regression discontinuity designs, possibly because these interventions do not use criteria that strictly partition participants and non-participants.

Table 6: Studies selected, by country, topic, and impact evaluation method

\begin{tabular}{|c|c|c|c|c|}
\hline & $\begin{array}{c}\text { Social } \\
\text { protection }\end{array}$ & Asset transfers & $\begin{array}{l}\text { Increasing } \\
\text { returns to } \\
\text { assets }\end{array}$ & Total \\
\hline \multicolumn{5}{|c|}{ Bangladesh } \\
\hline RCT & 2 & 3 & 0 & 5 \\
\hline Instrumental variables & 1 & 0 & 0 & 1 \\
\hline Regression discontinuity design & 0 & 0 & 0 & 0 \\
\hline Matching & 1 & 4 & 0 & 5 \\
\hline Other & 2 & 4 & 0 & 6 \\
\hline \multicolumn{5}{|c|}{ Ethiopia } \\
\hline RCT & 0 & 1 & 1 & 2 \\
\hline Instrumental variables & 0 & 0 & 1 & 1 \\
\hline Regression discontinuity design & 0 & 0 & 0 & 0 \\
\hline Matching & 3 & 2 & 2 & 7 \\
\hline Other & 4 & 0 & 1 & 5 \\
\hline \multicolumn{5}{|c|}{ Madagascar } \\
\hline RCT & 0 & 0 & 0 & 0 \\
\hline Instrumental variables & 0 & 0 & 0 & 0 \\
\hline Regression discontinuity design & 0 & 0 & 0 & 0 \\
\hline Matching & 0 & 0 & 0 & 0 \\
\hline Other & 0 & 0 & 0 & 0 \\
\hline \multicolumn{5}{|c|}{ Mozambique } \\
\hline
\end{tabular}




\begin{tabular}{|c|c|c|c|c|}
\hline & $\begin{array}{c}\text { Social } \\
\text { protection }\end{array}$ & Asset transfers & $\begin{array}{l}\text { Increasing } \\
\text { returns to } \\
\text { assets }\end{array}$ & Total \\
\hline RCT & 0 & 0 & 0 & 0 \\
\hline Instrumental variables & 0 & 0 & 0 & 0 \\
\hline Regression discontinuity design & 0 & 0 & 0 & 0 \\
\hline Matching & 0 & 0 & 2 & 2 \\
\hline Other & 2 & 0 & 0 & 2 \\
\hline \multicolumn{5}{|c|}{ Tanzania } \\
\hline RCT & 2 & 1 & 0 & 3 \\
\hline Instrumental variables & 0 & 0 & 0 & 0 \\
\hline Regression discontinuity design & 0 & 0 & 0 & 0 \\
\hline Matching & 0 & 1 & 1 & 2 \\
\hline Other & 0 & 1 & 0 & 1 \\
\hline \multicolumn{5}{|c|}{ All } \\
\hline RCT & 4 & 5 & 1 & 10 \\
\hline Instrumental variables & 1 & 0 & 1 & 2 \\
\hline Regression discontinuity design & 0 & 0 & 0 & 0 \\
\hline Matching & 4 & 7 & 5 & 16 \\
\hline Other & 8 & 5 & 1 & 14 \\
\hline
\end{tabular}

\section{What works to reduce poverty in Bangladesh?}

Seventeen studies on Bangladesh met our criteria for inclusion. Six studies look at the impact of social protection on poverty, consumption, and assets (Ferré and Sharif, 2014; Pradhan and Sulaiman, 2014; Ahmed et al., 2016; Sharif and Ruthbah, 2017; Cho and Ruthbah, 2018; and Ahmed et al. 2019) and 11 studies look at the impact of asset transfers on poverty, consumption, and assets (Das and Misha, 2010; Krishna et al., 2012; Raza and Ara, 2012; Raza et al., 2012: Das et al., 2013; Robano and Smith, 2013; Erman et al., 2014; Roy et al., 2015: Asadullah and Ara, 2016; Bandiera et al., 2017; and Balboni et al., 2020). There are no studies that look at the impact of increasing returns to assets on poverty. Nearly all of these studies are situated in rural areas that collectively cover much of the country. Out of the 17 studies on intervention examining what works to reduce poverty in Bangladesh, only one includes an urban area.

The six social protection programmes cover a range of interventions: conditional cash transfers (CCTs) (Ferré and Sharif, 2014); public works (Sharif and Ruthbah, 2017; Cho and Ruthbah, 2018); as well as cash and/or food transfers; sometimes twinned with training or behaviour change communication activities - the Vulnerable Group Development (VGD) 
programme (Pradhan and Sulaiman, 2014) and the Transfer Modality Research Initiative (Ahmed et al., 2016 and Ahmed et al., 2019). All interventions employed some form of targeting criteria and several, such as VGD and TMRI, explicitly focused on reaching poor women. Access to these interventions was typically time-bound. In the studies of these interventions, a variety of evaluation techniques were used, including RCTs and difference-indifferences.

All evaluations report that these social protection interventions increased household consumption expenditure, either by increasing food consumption, non-food consumption, or both. Two interventions, the VGD and the TMRI, reported increases in asset holdings; interestingly, these were both targeted to women. This is suggestive of sustained effects, but the absence of post-programme follow-up limits our ability to assess this. While these studies are well done, they have limitations. It would have been helpful to have more information on poverty impacts - we know these interventions increased consumption but only one, Pradhan and Sulaiman's (2014) evaluation of the VGD programme, assesses whether they lifted households above the poverty line. While all of the studies provide evidence on what works to reduce poverty in Bangladesh, differences in survey timing, evaluation techniques, and the location of the studies make it difficult (apart from the TMRI study, which directly contrasts food and cash transfers) to assess what 'works best' at reducing poverty in Bangladesh.

All studies examining the impact of asset transfers on poverty and consumption consider the same intervention, BRAC's Targeting the Ultra-Poor (TUP) programme. TUP has been implemented in several broadly similar phases. As suggested by the name of the programme, the poorest households in selected villages are targeted for inclusion. Women within these households choose from a menu of asset bundles valued at Bangladeshi Taka (BDT) 10,000 (approximately US\$ 500-600), though in practice nearly all choose livestock. Over a two-year period, they receive a broad range of skills training (general education, and health, legal, social, and political rights), as well as specific training on the asset they have been given. They also receive a small weekly stipend. They are encouraged to retain the asset for two years, to save with BRAC and to consider borrowing from BRAC microfinance at the end of the programme.

Evaluations of the first phase of the TUP programme use non-randomised methods, such as matching, while evaluations of the second phase take advantage of its randomised design. Both sets of evaluations find similar results. Access to the TUP programme increases consumption and asset holdings, with Robano and Smith (2013) also showing that it reduces multi-dimensional poverty, as measured by the Alkire-Foster indices. Bandiera et al. (2017) focus on the sustainability of impacts, using data collected seven years after treatment households entered the TUP programme. They find that relative to controls, the 
share of households below the US\$ 1.25 poverty line dropped by 8.4 percentage points, a 13.5\% decrease. Consumption expenditure per adult equivalent increased by US\$ 62.62 PPP. The value of household assets increased by US\$ 39.65 PPP compared to controls, a $57 \%$ increase. Livestock holdings in treatment households were higher than in control households, even after accounting for the value of the initial asset transfer. All of these impacts were statistically significant. Roy et al. (2015) note that the gendered aspects of these interventions were complex. Women retained control over the assets they had initially received but subsequent asset accumulation was often jointly owned, or controlled solely by men.

\section{What works to reduce poverty in Ethiopia?}

Fifteen studies on Ethiopia met our criteria for inclusion. Seven studies look at the impact of social protection on poverty, consumption, and assets (Sabates-Wheeler and Devereux, 2010; Berhane et al., 2012; Hoddinott et al., 2012; Berhane et al., 2014; Gebresilaisse, 2014; Berhane et al., 2015; and Kumar and Hoddinott, 2015); three studies look at the impact of asset transfers on poverty, consumption, and assets (Naga et al., 2010; Tilahun et al., 2016; and Blattman and Dercon, 2018); and five studies look at the impact of increasing returns to assets on poverty, consumption, and assets (Bacha et al., 2012; Hagos et al., 2012; Gebrehiwot, 2015; Verkaart et al., 2017; and Buehren et al., 2019).

Six out of the seven social protection studies focus on the Productive Safety Net Programme (PSNP), which is primarily a public works programme, although a small percentage of programme participants receive an unconditional cash transfer. Three of the studies also look at the joint impact of PSNP and an agricultural extension programme, either the Household Assets Building Program (HABP) or the Other Food Security Programme (OFSP). The results vary between the different studies. Sabates-Wheeler and Devereux (2010) evaluate the programme using panel data and find that consumption and productive assets increase for participants who received their payments in food, but not for beneficiaries who received their payments in cash. Berhane et al. (2012), Hoddinott et al. (2012), and Berhane et al. (2014) all use a difference-in-difference estimation. Berhane et al. (2012) find that productive assets increase for PSNP households. Specifically, participant households that receive payments for five years increase their livestock holdings by 0.372 Tropical Livestock Units (TLU), compared to households that only receive one year of payments (which is quite small). This result is statistically significant. There was no significant difference between PSNP households that received payments for five years and were part of agricultural extension programme and households that only received five years of PSNP payments. However, agricultural extension services and the social protection programme do increase investments in stone terracing, fencing, water harvesting, and the 
agricultural productivity of households, compared to just the social protection programme. Hoddinott et al. (2012) find similar results: for households with access to the agricultural extension programme, PSNP increases yields and the use of agricultural technology. Berhane et al. (2014) also find that livestock holdings increase for PSNP participants; however, there is not a statistically significant difference for households that participate in both PSNP and agricultural extension programmes compared to those which just have access to the agricultural extension programme. Hoddinott and Kumar (2015) and Gebresilassie (2014) use a weaker propensity score matching method to evaluate the programme. Gebresilassie (2014) finds that PSNP does not reduce poverty; however, participant households do increase their consumption and productive asset holdings. Hoddinott and Kumar (2015) focus on the regions of Afar and Somali, and do not find any significant impacts of the programme on asset holdings in these regions. The final social protection study, Berhane et al. (2015), looks at the pilot of a cash transfer programme in the Tigray region. Using a randomised design and a difference-in-difference estimation, the authors find that the cash transfer programme has no significant impacts on household consumption. However, households that receive the cash transfer are able to grow their farm productive assets and increase their ownership of durable goods, but the results depend on the region of study. In Hintalo Wajirat, ownership of productive assets for the farm increases by $1.9 \%$ and consumer durable goods increases by $0.8 \%$. Both of these results are statistically significant. While some of these programmes were implemented in both urban and rural regions, the results are not assessed separately by urban or rural locations. Similarly, no study assesses the impact of the programme separately for males or females.

Two studies look at the poverty impacts of agricultural assets or agricultural rights. Nega et al. (2010) look at the impact of an asset transfer programme where participants received credit for a package of goods (livestock, beehives, seed, and fertiliser) using propensity score matching. They find that participation in the programme reduces the poverty gap by 0.032 percentage points and reduces chronic poverty by 0.027 percentage points. Both results are statistically significant. They also report that the squared poverty gap is $18 \%$ lower for programme participants, and that participation reduces total poverty for the richest poor and reduces chronic poverty for the less-rich poor. Tilahun et al. (2016) look at the impact of belonging to a frankincense cooperative with the rights to frankincense forestland. Also using propensity score matching, they find that cooperative member households have lower instances of poverty. The poverty gap and the severity of poverty also decrease for member households. The other asset transfer study, Blattman and Dercon (2018), looks at the poverty impact of an entrepreneurship training programme and an unconditional cash grant. Programme participants indicated that they spent about $55 \%$ of the grant on business materials or investments. Using a randomised design, the authors of the study find that 
participation in the training programme increases weekly income by Ethiopian birr (ETB) 12 and household consumption by ETB 76. However, no impacts on poverty are reported.

All five studies in the increasing returns to assets category focus on agriculture. Two studies look at irrigation and water management technologies. Bacha et al. (2011) use the Heckman two-step technique and find that farmers with irrigation systems have higher household consumption. Hagos et al. (2012) use propensity score matching and find that water management systems decrease poverty and increase consumption. Depending on the type of system, water management systems decrease poverty by $9-37 \%$. Stochastic dominance tests also show a reduction in the depth and severity of poverty. One study looks at the poverty impact of improved varieties of chickpea. Using an instrumental variables approach, Verkaart et al. (2017) find that a 10\% increase in areas planted with improved varieties of chickpea decreases the probability of being in poverty by 3.9 percentage points. This result is statistically significant and is largest for households with smaller land holdings. Improved chickpeas also increase income. The two other studies look at the poverty impacts of agricultural extension programmes. Gebrehiwot (2015) uses a matching approach to evaluate the general agricultural extension programme. The author finds that participation in agricultural extension programmes increases household income and livestock holdings. Buehren et al. (2019) look at the Rural Capacity Building Project (RCBP), which ran from 2007 to 2011. Using a randomised design, they do not find any impact on assets or an overall impact on consumption. However, female-headed households in RCBP areas did increase their food consumption slightly. Poverty is not directly evaluated in either of the agricultural extension studies.

\section{What works to reduce poverty in Madagascar?}

There are no studies that met our criteria in Madagascar. In general, there is very little research on poverty interventions in Madagascar, and what little research does exist lacks robust evaluation methods. Madagascar does have multiple social protection programmes, but no study has undertaken an impact evaluation of these programmes. There is also a small literature looking at land rights in Madagascar; however, the results focus on productivity and not poverty measures. There is a large literature looking at the environment and climate change, but no connection to poverty is made. 


\section{$8 \quad$ What works to reduce extreme poverty in Mozambique?}

Four studies met our criteria for inclusion. Two studies (Soares et al., 2010; and Soares and Teixeira, 2010) look at the impact of social protection on consumption, and two studies look at increasing returns to assets (Cuguara and Moder, 2011; Cunguara and Darnhofer, 2011). The two social protection studies focus on the 2008 expansion of a food subsidy programme, the Food Subsidy Programme, that began in Mozambique in 1990. Both studies use a difference-in-difference design to assess the impacts of the programme. Soares et al. (2010) report that there was imperfect assignment to the treatment group, and that some households were not receiving the correct cash transfer amount. Soares and Teixeira (2010) focus on the implementation of the programme in rural areas. They find evidence that the programme increased food consumption. Treatment households experienced a $22 \%$ increase in food consumption relative to overall consumption, and the impact was higher for female-headed households as their food consumption increased $32 \%$ relative to overall consumption. These impacts on food consumption are statistically significant.

The other two studies look at the impacts of new knowledge or new technologies on household incomes of agricultural households in Mozambique. The results are mixed. Cuguara and Moder (2011) focus on new knowledge and look at the impact of a shift to extension services using the farmer field school approach. The authors are limited by their data and employ a cross-sectional matching estimator. They find that extension services increased household farm income by roughly $15 \%$. Cunguara and Darnhofer (2011) study new technologies by looking at the impacts of improved maize, animal traction, tractor mechanisation, and improved granaries on household income. Also using a matching estimator, they find no overall effect of these four different technologies on total household income. Breaking the results down by quantiles, they find surprising results. Tractor mechanisation and animal traction actually decrease household income for the poorest households; however, improved granaries increase household income for the poorest households.

\section{What works to reduce extreme poverty in Tanzania?}

Six studies satisfied our study criteria for inclusion. Two studies (Evans et al., 2014; Rosas et al., 2019) look at the impact of social protection on consumption and poverty. Four studies look at the impacts of increasing returns to either human capital or assets used in agricultural production. 
The two social protection studies focus on pilot social protection programmes: a CCT intervention that was implemented between 2010 and 2012, and an ongoing public works programme, the Tanzanian Productive Social Safety Net (PSSN), that incorporates a CCT and a public works component. Evans et al. (2014) assess the impacts of the CCT intervention on a wide range of poverty-related indicators using a cluster randomised design. They find scattered evidence of impacts on certain types of productive assets but no impact on household consumption/expenditure, and thus no impact on poverty. Rosas et al. (2019) examine the impacts of the PSSN on a range of indicators, also using a randomised (step wedge) design. They find evidence of impacts on purchases of inputs that increase agricultural production, and on the acquisition of productive assets. Rosas et al. (2019) report that treatment households increased their monthly consumption by Tanzanian shillings (TZS) 8,028 (roughly US\$ 3.4) per AEU, with both food and non-food consumption rising. Poverty was reduced by 10.1 percentage points. These impacts on consumption and poverty were all statistically significant. Although the PSSN was implemented in rural and urban areas, the study does not assess these impacts separately by rural/urban location. Two studies look at the poverty impacts of providing new knowledge or new technologies to Tanzanian households engaged in agriculture. The results are mixed. Larsen and Lilleor (2014) look at the impact of farmer field schools on food security and poverty using a difference-in-difference design. They find some evidence on metrics relating to food security but not poverty. Asfaw et al. (2012) look at the impact of introducing improved legumes (pigeon peas) in northern Tanzania. Data constraints force the authors to use a relatively weak impact approach - a cross-sectional matching estimator. With this caveat in mind, they find that adoption of pigeon peas reduces the depth of poverty by 8-10 percentage points and the severity of poverty by 4.4-8.1 percentage points. Two other studies look at the impact of interventions that aim to increase the return to human capital, either through technical and vocation training (TVET) or through providing vocational and life skills training to adolescent girls. Using observational data, Leyaro and Joseph (2019) report that receipt of TVET training increases wage income. Buehren et al. (2017) use a cluster randomised design to assess the impact of life skills, livelihood, and vocational training, all targeted towards adolescent girls. Older adolescents also received access to microfinance. The study shows that take-up of the intervention was low, less than $20 \%$, and there were no impacts on income or poverty. 


\section{What do we know about works to reduce extreme poverty in Bangladesh, Ethiopia, Madagascar, Mozambique, and Tanzania?}

In this paper we have undertaken a selective, structured literature review of what works to reduce poverty in five DEEP countries: Bangladesh, Ethiopia, Madagascar, Mozambique, and Tanzania. This selection covers a range of countries, in terms of geography and income levels. We examined three types of interventions that have plausible effects on poverty reduction: social protection; interventions that provide assets to poor households; and interventions that increase returns to assets.

We searched within Google Scholar and the World Bank e-Library for those studies that have an explicit focus on impacts on poverty as measured by consumption. We identified 111 such studies. We then assessed each paper against five inclusion criteria. These were: studies that consider poverty impacts, directly through poverty, consumption, or assets; studies that contain methods that are suitable for causal inference; studies that are not based solely on simulations; studies that undertake an impact evaluation; and studies that consider measurable outcomes and not only participant perceptions or preferences. Only 42 studies met all criteria.

The distribution of these studies across our five countries was uneven. 17 out of 42 were from Bangladesh (40.4\%) and another 15 were from Ethiopia (35.7\%). Studies from Mozambique and Tanzania comprised the remaining 23.8\%. There were no studies that met our inclusion criteria for Madagascar. Assessments of the poverty impacts of social protection interventions made up the largest proportion of the studies meeting all inclusion criteria, 40.4\%. Asset transfer studies were also well-represented, with 15 being included (35.7\%). However, there were only 10 studies that looked at the impact of interventions aimed at increasing returns to existing assets. Ethiopia was the only country where we had studies covering social protection, asset transfer, and increasing returns to assets. Asset transfers have been extensively studied in Bangladesh; these made up nearly all (11 our 14) of the asset transfer interventions that met our inclusion criteria. Out of the 17 studies on intervention examining what works to reduce poverty in Bangladesh, only one included an urban area.

Few studies, only five out of the 42 that met all inclusion criteria, assessed whether evaluations of 'what works' to reduce poverty consider the depth and severity of poverty, as well as its incidence. Few studies showed evidence of impacts disaggregated by sex. Sustainability was rarely examined in studies looking at social protection or at increased returns to assets. 
An objective of this study was to identify gaps where new work would be of value. The following would appear to be the largest gaps:

- There are few studies of what works to reduce poverty in Madagascar, Mozambique, and Tanzania. We note that our preliminary search.

- In all countries, we know little about what works to reduce poverty in urban areas.

- Few studies look at impacts after the intervention ends. Consequently, little is known about the sustainability of impacts.

- Assessment of the distributional aspects of interventions is often lacking. Studies may assess impacts on poverty metrics but not impacts on depth or severity of poverty. Little attention is paid to disaggregating impacts within the household.

- Lastly, we note that there is a striking lack of innovation in many of the interventions assessed by studies that met our criteria. With the exception - arguably - of the large asset transfer programmes found in Bangladesh and Ethiopia, the interventions used to reduce poverty in 2020 do not look that different from interventions used 10 or 20 years previously.

\section{References $^{2}$}

Alderman, H., Chiappori, P.A., Haddad, L., Hoddinott, J. and Kanbur, S.M.R. (1995) 'Unitary versus collective household models: Time to shift the burden of proof? World Bank Research Observer10(1), pp. 1-19.

Alkire, S. and Foster, J. (2011) 'Counting and Multidimensional Poverty Measurement', Journal of Public Economics 95, pp. 476-87.

Baulch, B. and Hoddinott, J. (2000) 'Economic mobility and poverty dynamics in developing countries', Journal of Development Studies 36(6), pp. 1-24.

Carter, M. and Barrett, C. (2006) 'The economics of poverty traps and persistent poverty: An asset-based approach', Journal of Development Studies 42(2), pp. 178-199.

Carney, D., Drinkwater, M., Rusinow, T., Neefjes, K., Wanmali, S. and Singh, N. (1999) 'Livelihoods approaches compared. A brief comparison of the livelihoods approaches of the U.K. Department for International Development (DfID), CARE, Oxfam, and the United Nations Development Programme (UNDP)', DFID, London.

DFID (1997) The UK white paper on international development-and beyond, DFID, London.

\footnotetext{
${ }^{2}$ These are the works cited in Sections 1 and 2. For references to the selected studies, see Annex A.
} 
Foster, J., Greer, J. and Thorbecke, E. (1984) 'A Class of Decomposable Poverty Measures', Econometrica 52, pp. 761-76.

Himmelfarb, G. (1984) The Idea of Poverty, Alfred Knopf, New York.

Heitzmann, K., Canagarajah, R.S. and Siegel, P.B. (2002) 'Guidelines for assessing the sources of risk and vulnerability', Social Protection Discussion Paper 0218, World Bank, Washington DC.

Hoddinott, J. (2012) 'Agriculture, health, and nutrition: Toward conceptualizing the linkages', in Reshaping agriculture for Nutrition and Health, International Food Policy Research Institute, Washington DC.

Hoddinott, J. and Quisumbing, A. (2010) 'Methods for microeconometric risk and vulnerability assessment', in Risk, Vulnerability and Human Development: On the brink, Palgrave Macmillan - United Nations Development Programme, London.

Lipton, M. and Ravallion, M. (1995) 'Poverty and policy', in Handbook of Development Economics 3(2), pp. 2551-2657, Elsevier, North Holland, Amsterdam.

Ravallion, M. (2015) The Economics of Poverty, Oxford University Press, New York.

Ravallion, M. (1994) 'Poverty comparisons: A guide to concepts and methods', Living Standards Measurement Study No. 88, World Bank, Washington DC.

Sen, A. (1985) Commodities and Capabilities, North-Holland, Amsterdam.

World Bank (2017) Monitoring Global Poverty: Report of the Commission on Global Poverty, World Bank, Washington, DC. 